\title{
Synthesis of Highly Emissive CdSe Quantum Dots by Aqueous Precipitation Method
}

\author{
Bing Gao, Chao Shen, Shuanglong Yuan, Yunxia Yang, and Guorong Chen \\ Key Laboratory for Ultrafine Materials of Ministry of Education, School of Materials Science and Engineering, \\ East China University of Science and Technology, Road Meilong Number 130, Shanghai 200237, China
}

Correspondence should be addressed to Yunxia Yang; yangyunxia@ecust.edu.cn

Received 3 August 2013; Accepted 25 September 2013

Academic Editor: Yanbao Zhao

Copyright (C) 2013 Bing Gao et al. This is an open access article distributed under the Creative Commons Attribution License, which permits unrestricted use, distribution, and reproduction in any medium, provided the original work is properly cited.

CdSe quantum dots (QDs) with high quantum yield (QY) up to $76.57 \%$ are synthesized using the aqueous precipitation method. With the control of $\mathrm{SeSO}_{3}{ }^{2-}$ concentration in Se precursor, the nucleation speed and concentration of CdSe QDs are increased. The mass of obtained $\mathrm{Cd}^{2+}$ and $\mathrm{Se}^{2+}$ in nanocrystal is measured by inductively coupled plasma atomic emission spectrometry (ICPAES). XRD and HRTEM are used to identify the crystal phase and morphology of the products which are pure CdSe crystals in the cubic zinc blende phase and uniformly dispersed in the solution with the size between $2 \mathrm{~nm}$ and $2.3 \mathrm{~nm}$. Results demonstrate that the emission wavelength of CdSe QDs is $500 \mathrm{~nm} \sim 560 \mathrm{~nm}$ along with the increased temperature $50^{\circ} \mathrm{C} \sim 90^{\circ} \mathrm{C}$ and prolonged time $5 \mathrm{~min} \sim 25 \mathrm{~min}$

\section{Introduction}

Because of excellent size-dependent optical characteristics and chemical treatability, semiconducting CdSe quantum dots (QDs) have been widely applied in biological identification (medical diagnosis), solar cells, optoelectronic devices, display instruments, nonlinear optical equipment, and magnetic materials [1-3]. In 1993, Murray et al. [4] firstly prepared CdSe QDs by using trioctylphosphine oxide (TOPO) and trioctylphosphine (TOP) as the solvent and obtained the very high fluorescence quantum yield (QY) up to $80 \%$ [5-7]. However, TOPO is highly toxic, explosive, and inflammable as well as expensive and difficult to control. Therefore, investigations on phosphine-free synthesis of CdSe QDs have attracted researchers' much attention in recent years. For example, Zhao et al. [8] obtained CdSe QDs with the ten carbonate cadmium of shorter carbon chain using cadmium oxide and decanoic acid as Cd precursor and the Se powder dispersed and dissolved by eighteen ene and eighteen amine as Se precursor, but QY decreased to about $50 \%$. To be further closer to the standard of green chemistry in preparation of CdSe QDs, the low-temperature aqueous phase method was developed, which, besides nontoxicity, has advantages of lower cost, simple synthesis process, and the improved stability of CdSe QDs [9-11]. But QY of products was reduced even lower, generally $30 \%$ or less $[12,13]$. In this context, it is essential as well as challenging to increase QY of CdSe QDs synthesized by the aqueous phase method.

In the present work, the effective aqueous precipitation method has been explored where the control of $\mathrm{SeSO}_{3}{ }^{2-}$ concentration in Se precursor was especially emphasized in order to realize speed-up of the nucleation of the products and increase of the concentration of CdSe QDs. We have demonstrated QY of the synthesized CdSe QDs maximum to $76.57 \%$ and discussed the relevant mechanism.

\section{Experimental}

The Se precursor for the present work was prepared by mixing the selenium powder $(0.005 \mathrm{~mol})$ (A.R, Shanghai Meixing Chemical Co., Ltd.), sodium sulfite $(0.01 \mathrm{~mol})$ (A.R, Sinopharm Chemical Reagent Co., Ltd.), sodium hydroxide $(0.01 \mathrm{~mol})$ (A.R, Shanghai Aijian ready-made Reagent Co., Ltd.), and deionized water $(50 \mathrm{~mL})$ with $\mathrm{N}_{2}$ protection and magnetic stirring. The mixture was heated to boiling while the solution turned from red brown to the black precipitate. Then sodium hydroxide $(0.01 \mathrm{~mol})$ was added, and after returning for 4 hours, the reactants were cooled down 


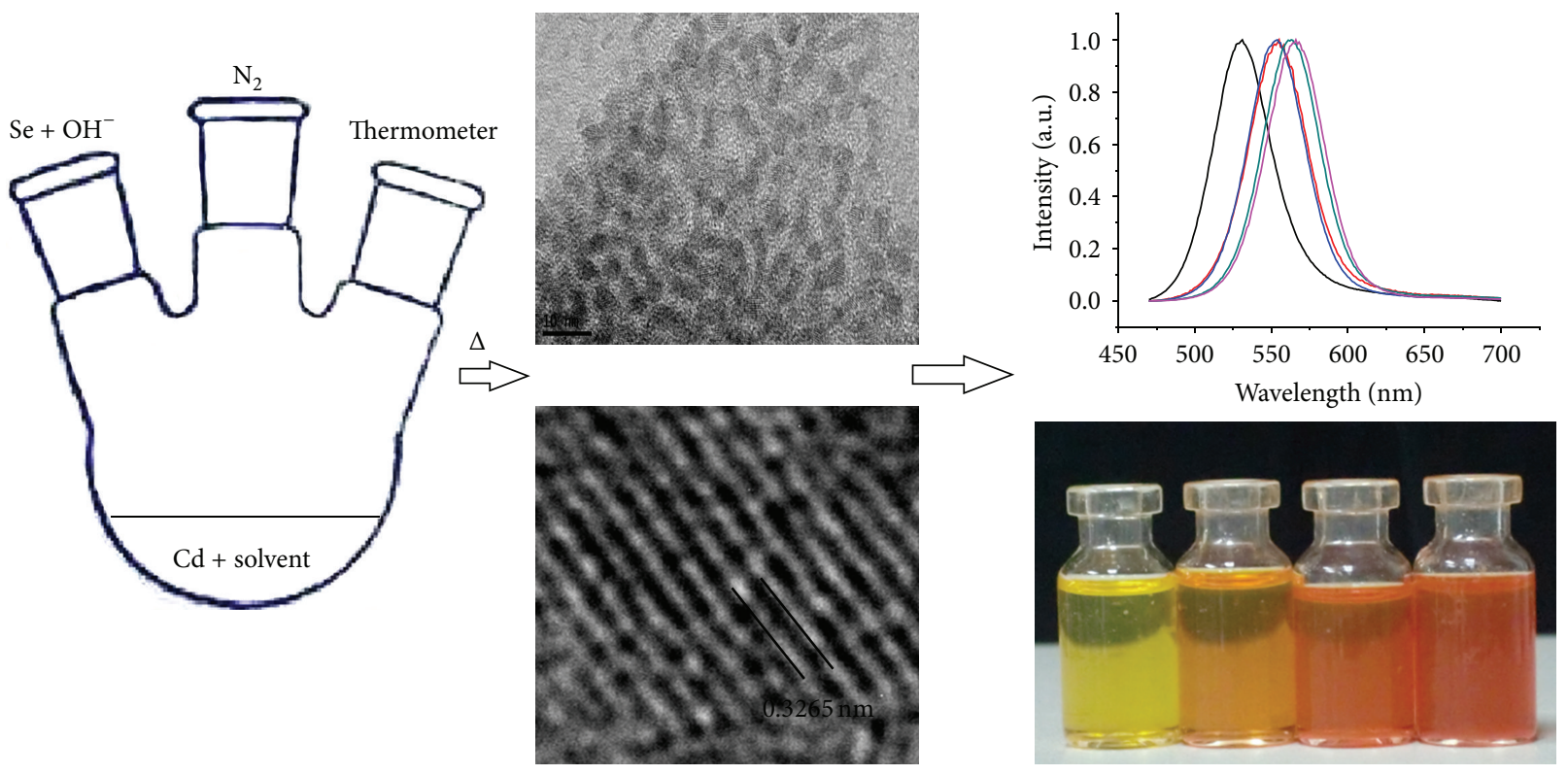

Figure 1: The flow diagram of the whole reaction.

TABLE 1: Sample numbers and reaction temperature and time.

\begin{tabular}{lccccc}
\hline Temperature & \multicolumn{5}{c}{ Time } \\
& $5 \mathrm{~min}$ & $10 \mathrm{~min}$ & $15 \mathrm{~min}$ & $20 \mathrm{~min}$ & $25 \mathrm{~min}$ \\
\hline $50^{\circ} \mathrm{C}$ & I1 & I2 & I3 & I4 & I5 \\
$70^{\circ} \mathrm{C}$ & II 1 & II 2 & II3 & II 4 & II5 \\
$90^{\circ} \mathrm{C}$ & III 1 & III2 & III3 & III4 & III5 \\
\hline
\end{tabular}

to the room temperature followed by nitrogen protection for $30 \mathrm{~min}$.

The Cd precursor was prepared by mixing water, ethanol, and oleic acid (A.R, Jiangsu Yonghua Fine Chemicals Co., Ltd.) together in volume ratio of $10: 30: 8$. Cadmium acetate $0.001 \mathrm{~mol}$ (A.R, Sinopharm Chemical Reagent Co., Ltd.) and sodium hydroxide $(0.7 \mathrm{~g})$ were added as precipitation agents to the mixed solvent $(48 \mathrm{~mL})$. The mixture was under the $\mathrm{N}_{2}$ protection until it became clear and transparent. The reaction temperature was $50^{\circ} \mathrm{C}, 70^{\circ} \mathrm{C}$, and $90^{\circ} \mathrm{C}$.

The CdSe QDs were synthesized by adding $10 \mathrm{ml}$ Se precursor solution to the $48 \mathrm{~mL} \mathrm{Cd}$ precursor solution, under $\mathrm{N}_{2}$ protection and magnetic stirring. The reactions were carried out at $50^{\circ} \mathrm{C}, 70^{\circ} \mathrm{C}$, and $90^{\circ} \mathrm{C}$ for $5 \mathrm{~min}, 10 \mathrm{~min}, 15 \mathrm{~min}$, $20 \mathrm{~min}$, and $25 \mathrm{~min}$, respectively, as marked in Table 1 . The samples were centrifuged with ethanol and dispersed in hexane.

$\mathrm{X}$-ray diffraction spectra (XRD, D/MAX $2550 \mathrm{VB} / \mathrm{PC}$, Japan, RIGAKU) $\left(\lambda_{\mathrm{Cu}}=0.15406 \mathrm{~nm}\right)$ were recorded to identify the crystal phase and size. The high resolution transmission electron microscopy (HRTEM) (JEM-201, American FEI company) was used to characterize the morphology and structure of the samples. The optical absorption spectra (a Lambda 950 UV-Visible Spectrophotometer, Perkin Elmer, Waltham, MA) and the photoluminescent (PL) spectra (model Fluorolog-3-P, France Jobin Yvon company, model Cary 500, American Varian company) were measured for

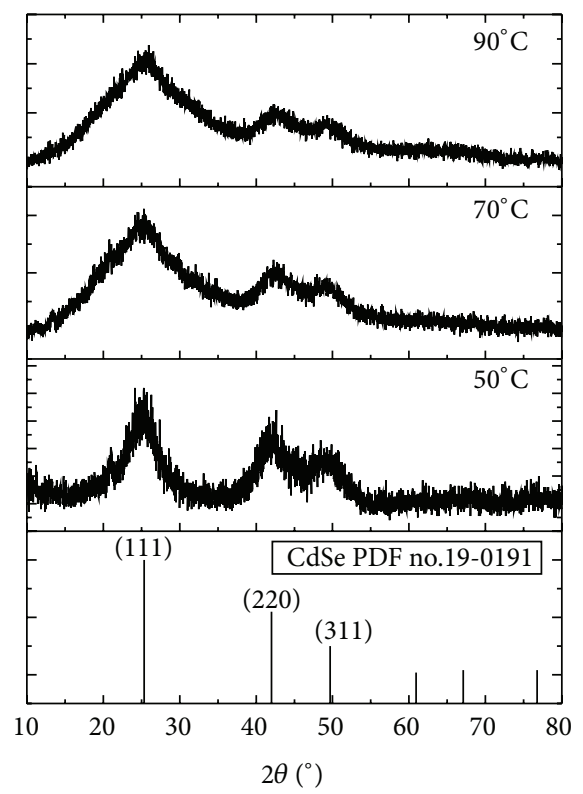

FIGURE 2: XRD patterns of sample I1, IIl, and III1 $\left(50^{\circ} \mathrm{C}, 70^{\circ} \mathrm{C}\right.$, and $\left.90^{\circ} \mathrm{C}\right)$.

calculation of QY according to the absorption coefficient and integrated emission area. The mass of obtained $\mathrm{Cd}^{2+}$ and $\mathrm{Se}^{2+}$ in nanocrystal is measured by inductively coupled plasma atomic emission spectrometry (ICP-AES) (model IRIS 1000). The flow diagram of the reaction is shown in Figure 1.

\section{Results and Discussion}

Figure 2 presents the XRD spectra of samples I1, III, and IIII for crystal phase identification, where the XRD profile of CdSe crystals in the cubic zinc blende phase (JCPDS file no. 
TABLE 2: Calculated diameters of CdSe crystals in sample $\mathrm{I} 1\left(50^{\circ} \mathrm{C}\right)$.

\begin{tabular}{lccc}
\hline $2 \theta$ & $25.30^{\circ}$ & $42.24^{\circ}$ & $49.23^{\circ}$ \\
$\theta$ & $12.65^{\circ}$ & 21.12 & 24.62 \\
FWHM $\left(^{\circ}\right)$ & 10.3 & 4.73 & 2.98 \\
FWHM (rad) & 0.18 & 0.08 & 0.05 \\
Radius $(\mathrm{nm})$ & 0.78 & 1.80 & 2.95 \\
Average radius $(\mathrm{nm})$ & & $1.84 \mathrm{~nm}$ & \\
\hline
\end{tabular}

TABLE 3: Calculated diameters of CdSe crystals in sample II1 $\left(70^{\circ} \mathrm{C}\right)$.

\begin{tabular}{lrcc}
\hline $2 \theta$ & $25.37^{\circ}$ & $42.04^{\circ}$ & $49.74^{\circ}$ \\
$\theta$ & $12.69^{\circ}$ & 21.02 & 24.87 \\
FWHM $\left(^{\circ}\right)$ & 3.51 & 4.11 & 5.10 \\
FWHM (rad) & 0.08 & 0.07 & 0.09 \\
Radius $(\mathrm{nm})$ & 2.34 & 2.10 & 1.68 \\
Average radius $(\mathrm{nm})$ & & $2.04 \mathrm{~nm}$ & \\
\hline
\end{tabular}

TABLE 4: Calculated diameters of CdSe crystals in sample III1 $\left(90^{\circ} \mathrm{C}\right)$.

\begin{tabular}{lccc}
\hline $2 \theta$ & $25.51^{\circ}$ & $42.56^{\circ}$ & $49.25^{\circ}$ \\
$\theta$ & $12.76^{\circ}$ & 21.28 & 24.63 \\
FWHM $\left(^{\circ}\right)$ & 11.53 & 3.72 & 2.56 \\
FWHM $(\mathrm{rad})$ & 0.20 & 0.06 & 0.04 \\
Radius $(\mathrm{nm})$ & 0.70 & 2.43 & 3.69 \\
Average radius $(\mathrm{nm})$ & & $2.27 \mathrm{~nm}$ & \\
\hline
\end{tabular}

19-0191) is included at the bottom as the reference. Three main diffraction peaks are clearly identical at around $25.18^{\circ}, 42.31^{\circ}$, and $49.52^{\circ}$, coinciding with those of CdSe crystals having different crystal planes (111), (220), and (311), respectively. No diffraction peak of other crystal phase is discovered in Figure 2, indicating that the structure with pure CdSe crystals was obtained.

The average diameter of CdSe crystals in sample I1, II1, and IIII is calculated according to the broadening of XRD by the Scherrer formula $D=k \lambda / \beta \cos \theta$, where $\lambda=0.15406 \mathrm{~nm}$, $\beta$ is the full wavelength at half maximum (FWHM) of diffraction peak (in Radian), and $k$ is a constant (0.89) [13]. The calculated results are given in Tables 2,3 , and 4, where the estimated average grain diameter of CdSe QD is about $1.84 \mathrm{~nm}, 2.04 \mathrm{~nm}$, and $2.27 \mathrm{~nm}$, respectively.

HRTEM photos of samples I1, I3, I5; II1, II3, II5 and III1, III3, III5 are presented in Figures 3(a)-3(i). With the reaction temperature increasing from $50^{\circ} \mathrm{C}$ and $70^{\circ} \mathrm{C}$ to $90^{\circ} \mathrm{C}$, the size of CdSe QDs becomes larger from $2.1 \mathrm{~nm}$ and $2.13 \mathrm{~nm}$ to $2.3 \mathrm{~nm}$, respectively, which are consistent with the results to $\mathrm{XRD}$. It is seen that the precipitated CdSe QDs in the three samples are dispersed uniformly.

Furthermore, HRTEM photos of samples I1, II1, and III1 for lattice parameter analysis are provided in Figure 4. It is seen from the figure that the interplanar spacing of CdSe QDs in samples with the different reaction time is close to each other $(0.3165 \mathrm{~nm}, 0.3162 \mathrm{~nm}$, and $0.3265 \mathrm{~nm})$, and they are all close to the interplanar spacing $(0.35145 \mathrm{~nm})$ of the (111) CdSe crystal plane corresponding to the strongest diffraction peak at $2 \theta=25.321^{\circ}$ in XRD. This result further demonstrates that the obtained products are CdSe crystal phase.

Figure 5 shows the absorption spectra of samples I1 I5, II1 II5, and III1 III5. An absorption peak appears at $450 \mathrm{~nm}$, $475 \mathrm{~nm}$, and $510 \mathrm{~nm}$, respectively, suffering an obvious blue shift compared with that of the bulk CdSe $(717 \mathrm{~nm})$. Such a blue shift (or band-gap broadening) phenomenon occurs as a consequence of the quantum size effect, showing that the products are already in nanoscale. However, with the reaction temperature increasing, the quantum size effect reduces due to the growing size of products, leading to the red shift of the absorption peak or narrowing of the band-gap.

Figures 6(a), 6(b), and 6(c) show the normalized emission spectra of samples under different reaction temperature and time. For all three groups, under the excitation of blue light $(460 \mathrm{~nm})$, a broad emission band is observed peaking in the green region and showing obvious red shift with the increasing reaction time. Taking the $50^{\circ} \mathrm{C}$ group (a) as an example, it is seen that the emission peak is, respectively, at $500 \mathrm{~nm}, 502 \mathrm{~nm}, 505 \mathrm{~nm}, 509 \mathrm{~nm}$, and $513 \mathrm{~nm}$, corresponding to the reaction time changing from $5 \mathrm{~min}$ to $25 \mathrm{~min}$ with an increase of $5 \mathrm{~min}$ each. The reaction temperature exerts the same effect on the emission spectra of samples under $70^{\circ} \mathrm{C}$ and $90^{\circ} \mathrm{C}$, shown in Figures 6(b) and 6(c); that is, the red shift occurs from $500 \mathrm{~nm}$ to $533 \mathrm{~nm}\left(70^{\circ} \mathrm{C}\right)$ and $510 \mathrm{~nm}$ to $560 \mathrm{~nm}\left(90^{\circ} \mathrm{C}\right)$, respectively. Similar to analysis on the absorption spectra above, the regular red shift of the emission band is due to the increase of grain size and the decrease of the band gap. Because the luminescence essence of the semiconducting CdSe QDs is the transition probability of the electrons in the band gap, along with the increased crystal size of products due to the prolonged reaction time and the increasing reaction temperature, the band gap of the products becomes narrower, leading to the red shift of emission wavelength. Figure 6(d) shows the real colour of samples under different temperature in daylight, which are yellow and orange to red.

It is known via previously reported work that QY of CdSe QDs can be calculated according to formula (1) with rhodamine $B$ as reference object $[8,14]$ :

$$
Y_{\mathrm{Q}}=Y_{R} \times \frac{I_{\mathrm{Q}}}{I_{R}} \times \frac{A_{R}}{A_{\mathrm{Q}}} \times \frac{N_{\mathrm{Q}}{ }^{2}}{N_{R}{ }^{2}},
$$

where $Y_{R}$ is the standard QY (95\%) of rhodamine B, $I_{\mathrm{Q}}$ and $I_{R}$ represent the integral emission areas of CdSe QDs and rhodamine B under $460 \mathrm{~nm}$ excitation, respectively, $A_{R}$ and $A_{Q}$ are the absorption coefficients (around 0.05 or less than $0.05)$ of the rhodamine B and CdSe QDs at $460 \mathrm{~nm}[15,16]$, and $N_{Q}$ and $N_{R}$ are refractive indices of the n-hexane (1.375) and ethanol (1.362) used as the solvent for the CdSe QDs and rhodamine $\mathrm{B}$.

The absorption coefficients of samples I1, II1, and III1 and rhodamine $\mathrm{B}$ at $460 \mathrm{~nm}$ are $0.0287,0.0565,0.0530$, and 0.0139 , corresponding to their integral emission areas of $1.29 \times 10^{7}$, $1.76 \times 10^{7}, 1.17 \times 10^{7}$, and $7.9 \times 10^{6}$, respectively, under the $460 \mathrm{~nm}$ excitation. According to these data, QY of samples I1, III, and IIIl are calculated via formula (1) as 76.57\%, 53.07\% and $37.61 \%$. 


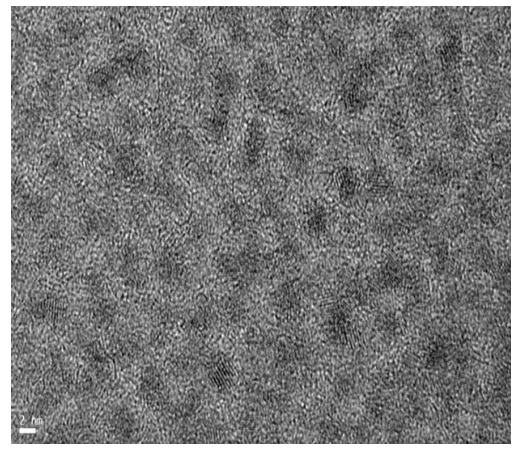

(a) $\mathrm{Il}\left(50^{\circ} \mathrm{C}\right)$

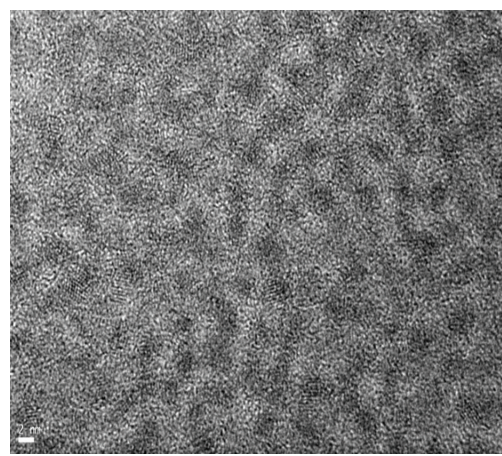

(d) $\operatorname{II1}\left(70^{\circ} \mathrm{C}\right)$

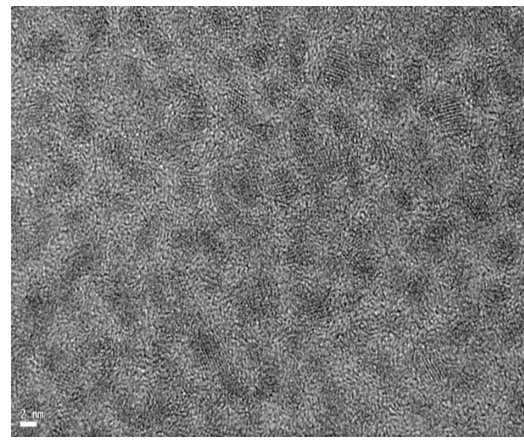

(g) $\operatorname{III1}\left(90^{\circ} \mathrm{C}\right)$

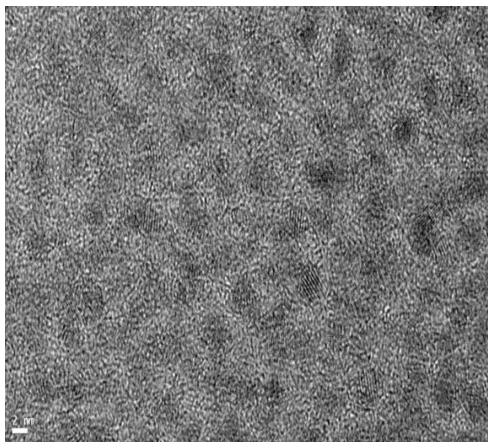

(b) $\mathrm{I} 3\left(50^{\circ} \mathrm{C}\right)$

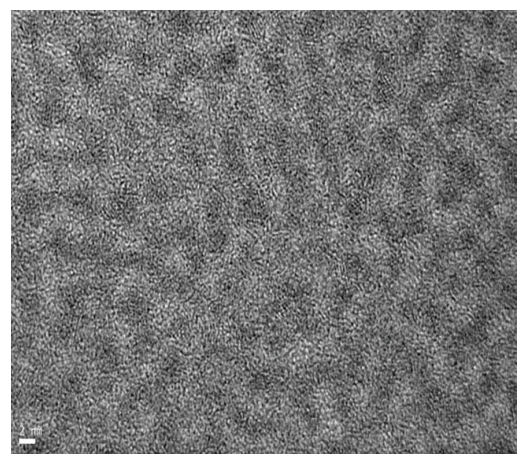

(e) $\mathrm{II} 3\left(70^{\circ} \mathrm{C}\right)$

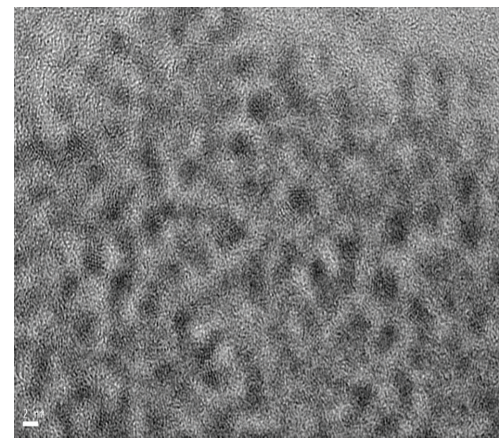

(h) $\operatorname{III} 3\left(90^{\circ} \mathrm{C}\right)$

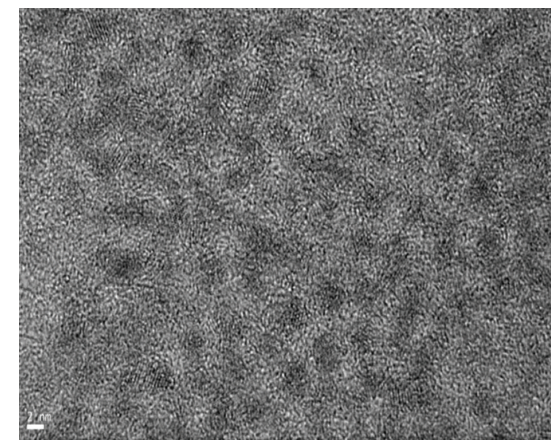

(c) $\mathrm{I} 5\left(50^{\circ} \mathrm{C}\right)$

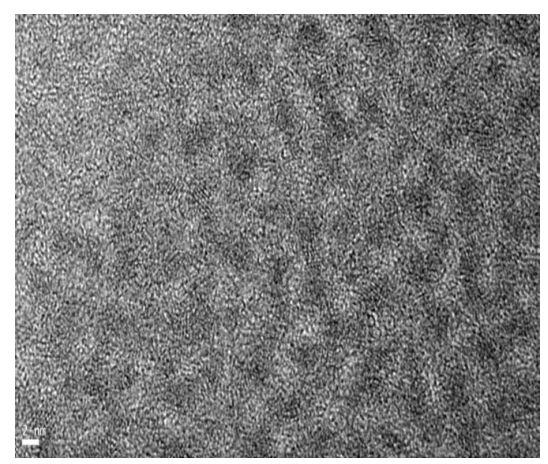

(f) $\mathrm{II} 5\left(70^{\circ} \mathrm{C}\right)$

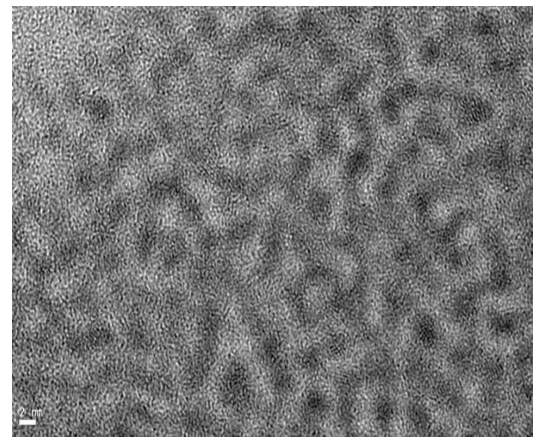

(i) $\operatorname{III} 5\left(90^{\circ} \mathrm{C}\right)$

FIgURE 3: HRTEM photos of samples I1, I3, I5, II1, II3, II5, III1, III3, and III5.

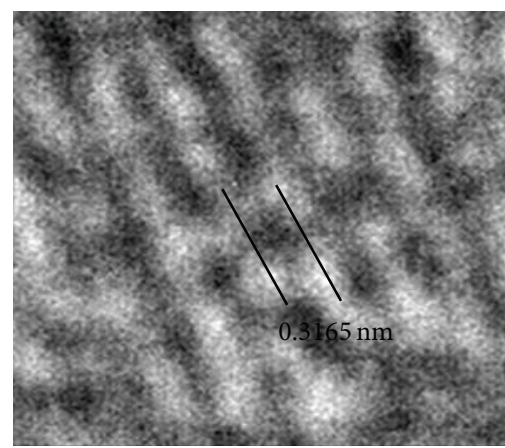

(a) I1 $\left(50^{\circ} \mathrm{C}\right)$

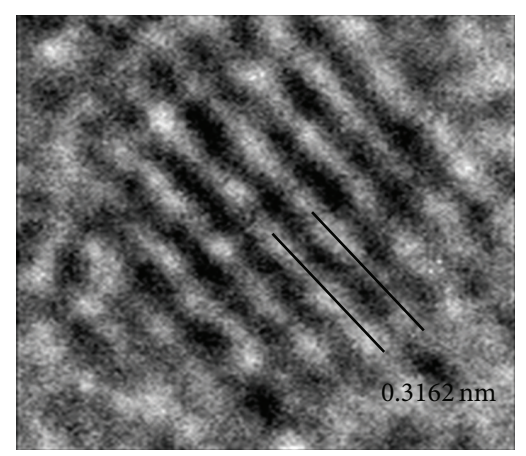

(b) $\mathrm{II1}\left(70^{\circ} \mathrm{C}\right)$

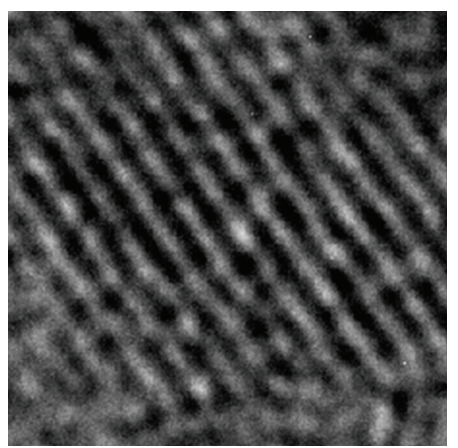

(c) $\operatorname{IIII}\left(90^{\circ} \mathrm{C}\right)$

FIGURE 4: HRTEM photos of samples I1, II1, and III1 for lattice parameter analysis. 


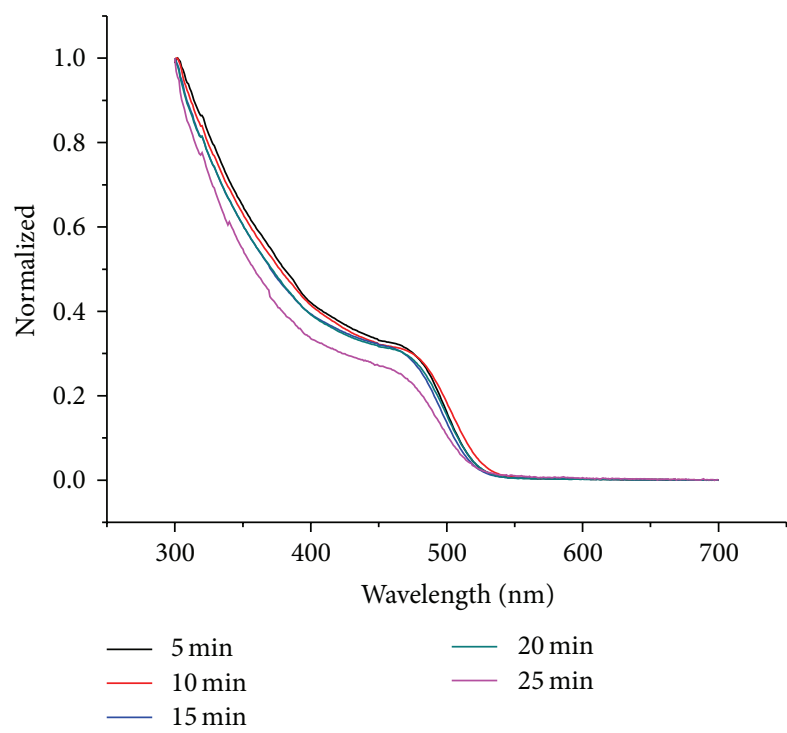

(a) $50^{\circ} \mathrm{C}$

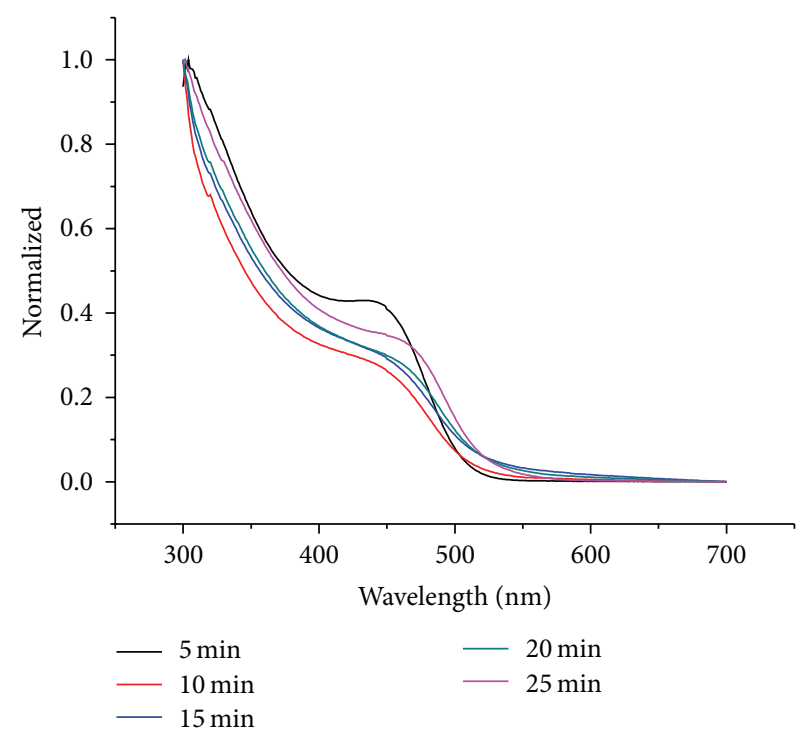

(b) $70^{\circ} \mathrm{C}$

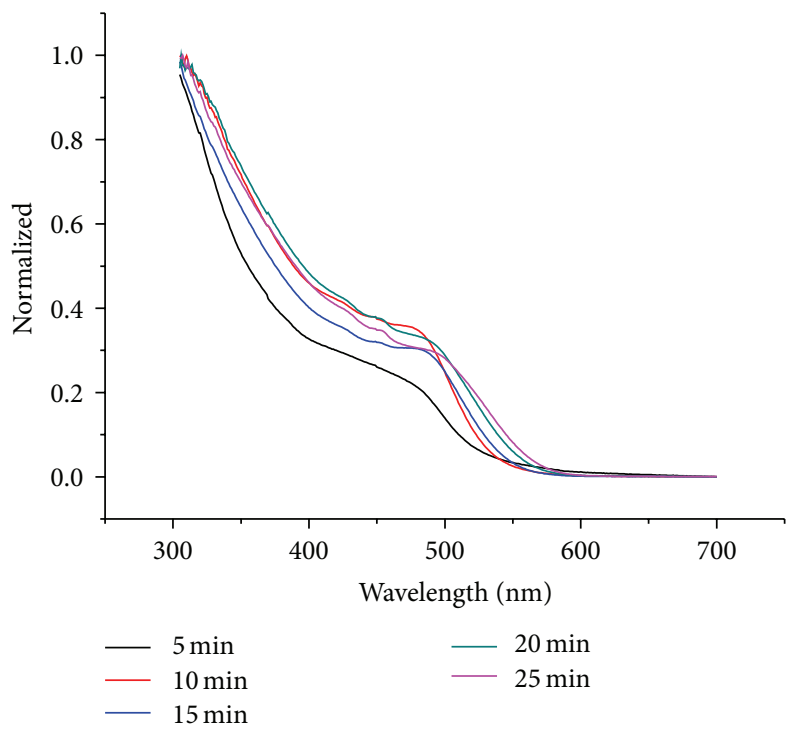

(c) $90^{\circ} \mathrm{C}$

FIgURE 5: Absorption spectra of samples under different reaction temperature and time (a) $50^{\circ} \mathrm{C}$, (b) $70^{\circ} \mathrm{C}$, and (c) $90^{\circ} \mathrm{C}$.

It is obvious that along with the increased crystal size of CdSe QDs in the samples, QY decreases from 76.57\% (I1) to $37.61 \%$ (IIII) most likely due to the reduced quantum confinement effect. However, in the present work, QY of sample I1 reaches the level of $76.57 \%$, much higher than those $(\sim 30 \%)$ reported with the aqueous precipitation method [13]. The main reason is due to the nearly complete reaction of Se precursor which much enhances the luminescence of CdSe QDs.

In our work, black powders were precipitated in preparation of the Se precursor. According to the principle of chemical reaction [17], the red selenium precipitation occurs when selenite solution meets the reducing agent in acid solution and turns to black after being heated. So it can be inferred that the black precipitate is the unreacted Se powder. The selenium precipitation reduces the concentration of $\mathrm{Se}^{2-}$ in the solution and makes the stoichiometric ratio inaccurate, which consequently affects the reaction speed and final concentration of CdSe QDs in the solution.

It is known that thiosulfate $\mathrm{S}_{2} \mathrm{O}_{3}{ }^{2-}$ tends to decompose into sulfur and sulfurous acid in the acid solution, while it is stable in alkaline solution or alkali metal thiosulfate solution [17]. Similarly, instability of $\mathrm{SeSO}_{3}{ }^{2-}$ in the present work could be overcome by the addition of $\mathrm{OH}^{-}$to the Se precursor, guaranteeing the nearly-complete reaction of Se source. Also, consider the following reaction equations [18]:

$$
\begin{gathered}
\mathrm{Se}+\mathrm{SO}_{3}{ }^{2-} \longrightarrow \mathrm{SeSO}_{3}{ }^{2-} \\
\mathrm{SeSO}_{3}{ }^{2-}+\mathrm{OH}^{-} \longrightarrow \mathrm{HSe}^{-}+\mathrm{SO}_{4}{ }^{2-}
\end{gathered}
$$




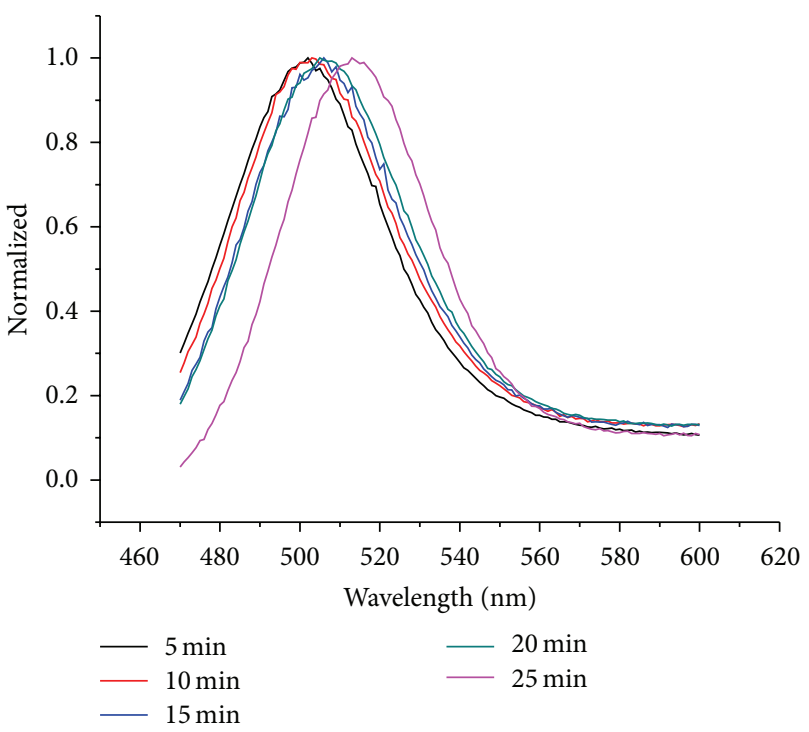

(a) $50^{\circ} \mathrm{C}$

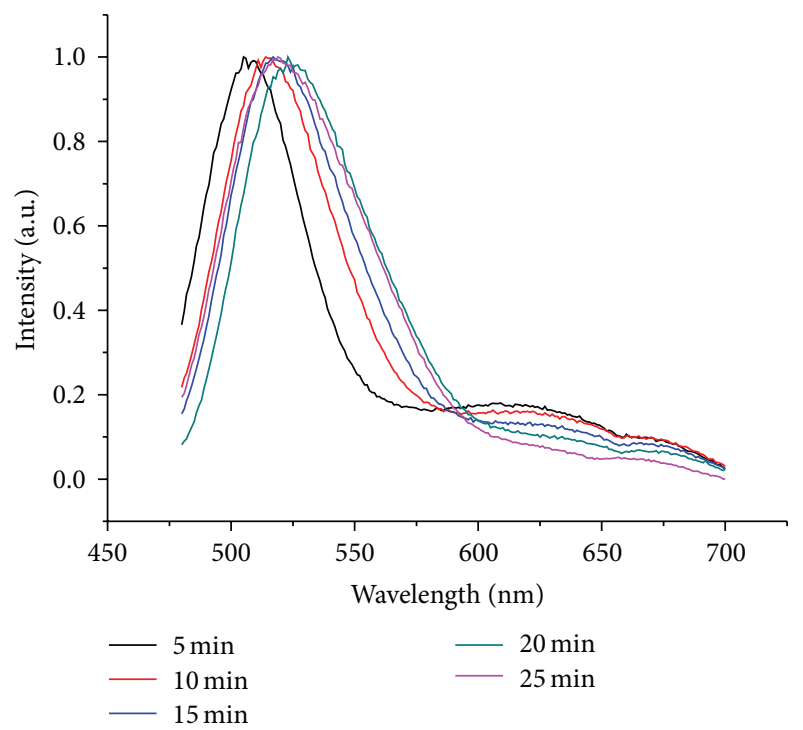

(c) $90^{\circ} \mathrm{C}$



(b) $70^{\circ} \mathrm{C}$



(d) real samples

Figure 6: The emission spectra of samples under different reaction temperature and time ((a), (b), and (c); $50^{\circ} \mathrm{C}, 70^{\circ} \mathrm{C}$, and $\left.90^{\circ} \mathrm{C}\right)\left(\lambda_{\text {ex }}=\right.$ $460 \mathrm{~nm}$ ) and the picture of real samples (d).

TABle 5: Determined $\mathrm{Cd}^{2+}$ and $\mathrm{Se}^{2+} \%$ from ICP-AES analysis for sample I1 (50 $\left.{ }^{\circ} \mathrm{C}, 5 \mathrm{~min}\right)$.

\begin{tabular}{lccccc}
\hline Cd source & Se source & $\mathrm{Cd}^{2+}$ (tested by ICP) & $\mathrm{Se}^{2+}$ (tested by ICP) & $\mathrm{Cd}^{2+}$ (in CdSe) & Se $^{2+}$ (in CdSe and unreacted to CdSe) \\
\hline $112 \mathrm{mg}$ & $79 \mathrm{mg}$ & $4.68 \mathrm{mg}$ & $0.56 \mathrm{mg}$ & $95.82 \%$ & $99.29 \%$ \\
\hline
\end{tabular}

$$
\begin{gathered}
\mathrm{HSe}^{-}+\mathrm{OH}^{-} \longrightarrow \mathrm{Se}^{2-}+\mathrm{H}_{2} \mathrm{O} \\
\mathrm{Cd}^{2+}+\mathrm{Se}^{2-} \longrightarrow \mathrm{CdSe}
\end{gathered}
$$

$\mathrm{OH}^{-}$encourages the production of $\mathrm{Se}^{2-}$ from $\mathrm{SeSO}_{3}{ }^{2-}$ to form $\mathrm{CdSe} \mathrm{QDs}$ with $\mathrm{Cd}^{2+}$. So we add $\mathrm{NaOH}$ to Se precursor, and thus, Se powder nearly disappears.

The masses of $\mathrm{Cd}^{2+}$ and $\mathrm{Se}^{2+}$ obtained from sample I1 (in solution) are measured by inductively coupled plasma atomic emission spectrometry (ICP-AES) shown in Table 5.
The masses of Cd and Se source are $112 \mathrm{mg}$ and $79 \mathrm{mg}$, and the qualities of $\mathrm{Cd}^{2+}$ and $\mathrm{Se}^{2+}$ in ICP test are $4.68 \mathrm{mg}$ and $0.56 \mathrm{mg}$. The calculated proportion of $\mathrm{Cd}^{2+}$ in CdSe nanocrystal is $95.82 \%$, and the total proportion of $\mathrm{Se}^{2+}$ in nanocrystal and unreacted to CdSe nanocrystal is $99.29 \%$.

On the other hand, by taking $\mathrm{Cd}^{2+}+\mathrm{Se}^{2-} \rightarrow \mathrm{CdSe} \downarrow$ as an elementary reaction, to make $0.005 \mathrm{~mol}$ Se powder react completely, $0.01 \mathrm{~mol} \mathrm{OH}^{-}$is required. In the case without $\mathrm{NaOH}$, there is only $5 \times 10^{-9}\left(0.05 \times 10^{-7}\right) \mathrm{mol} \mathrm{OH}^{-}$in 
the $50 \mathrm{~mL}$ water. The addition of $\mathrm{NaOH}$ provides enough $\mathrm{OH}^{-}$. According to the reaction rate equations of $\mathrm{V}=$ $\mathrm{K}\left[\mathrm{Cd}^{2+}\right]\left[\mathrm{Se}^{2-}\right]$, the content of $\mathrm{OH}^{-}$is $2 \times 10^{6}$ times as much as that in water. The increase of $\mathrm{Se}^{2-}$ concentration speeds up the nucleation process of CdSe QDs and increases the concentration of the products, which leads to the high QY of CdSe QDs.

\section{Conclusion}

In this paper, CdSe quantum dots (QDs) are produced using an aqueous precipitation method. XRD patterns demonstrate the structure of products with the purely precipitated CdSe crystals. TEM manifests that the size of the CdSe QDs is between $2 \mathrm{~nm}$ and $2.3 \mathrm{~nm}$ with good monodispersity. The addition of $\mathrm{NaOH}$ to Se precursor speeds up the nucleation and increases the concentration of CdSe QDs. The ICPAES shows that the calculated proportion of $\mathrm{Cd}^{2+}$ in CdSe nanocrystal is $95.82 \%$, and the total proportion of $\mathrm{Se}^{2+}$ in nanocrystal and unreacted to CdSe nanocrystal is $99.29 \%$. Furthermore, the band gaps of QDs blue shift compared to the CdSe bulk material show that the products are already in nanoscale. The photoluminescence spectra show the broad emission band centering at $500 \mathrm{~nm} \sim 560 \mathrm{~nm}$, depending on the size of the CdSe QDs. QY of CdSe QDs increases steadily along with the decreased crystal size with the maximum up to $76.57 \%$. The CdSe QDs prepared in this paper with the environmental friendly method can probably be applied in the fields of LED and biological identification because of the high QY.

In this paper, CdSe quantum dots (QDs) with high quantum yield (QY) up to $76.57 \%$ are synthesized using the aqueous precipitation method. With the control of $\mathrm{SeSO}_{3}{ }^{2-}$ concentration in Se precursor, the nucleation speed and concentration of CdSe QDs are increased, and the quantum yield of the CdSe QDs is increased. Although the CdSe QDs have been studied for many years, we use the basis chemical knowledge to improve the photoluminescent property of the CdSe QDs. We propose the power of the basic chemistry.

\section{Acknowledgment}

This study was supported by Shanghai Leading Academic Discipline Project (No. B502), Shanghai Key Laboratory Project (08DZ2230500), Doctoral Fund of Ministry of Education of China (20120074110018) and the National Natural Science Foundation of China (NSFC 51072052).

\section{References}

[1] D. Shi, N. M. Bedford, and H.-S. Cho, "Engineered multifunctional nanocarriers for cancer diagnosis and therapeutics," Small, vol. 7, no. 18, pp. 2549-2567, 2011.

[2] S. Jeong, J. S. Lee, J. Nam et al., "One-step preparation of strongly luminescent and highly loaded CdSe quantum dot-silica films," Journal of Physical Chemistry C, vol. 114, no. 34, pp. 14362-14367, 2010.
[3] J. Wang, M. Lin, Y. Yan, Z. Wang, P. C. Ho, and P. L. Kian, "CdSe/AsS core-shell quantum dots: Preparation and twophoton fluorescence," Journal of the American Chemical Society, vol. 131, no. 32, pp. 11300-11301, 2009.

[4] C. B. Murray, D. J. Norris, and M. G. Bawendi, "Synthesis and characterization of nearly monodisperse $\mathrm{CdE}(\mathrm{E}=\mathrm{S}$, Se, Te) semiconductor nanocrystallites," Journal of the American Chemical Society, vol. 115, no. 19, pp. 8706-8715, 1993.

[5] A. J. Morris-Cohen, M. D. Donakowski, K. E. Knowles, and E. A. Weiss, "The effect of a common purification procedure on the chemical composition of the surfaces of cdse quantum dots synthesized with trioctylphosphine oxide," Journal of Physical Chemistry C, vol. 114, no. 2, pp. 897-906, 2010.

[6] S. Corneliu Stan, S. Marius Secula, and D. Sibiescu, "Highly luminescent polystyrene embedded CdSe quantum dots obtained through a modified colloidal synthesis route," Electronic Materials Letters, vol. 8, no. 3, pp. 275-281, 2012.

[7] J. Bomm, A. Büchtemann, A. Fiore et al., "Fabrication and spectroscopic studies on highly luminescent $\mathrm{CdSe} / \mathrm{CdS}$ nanorod polymer composites," Beilstein Journal of Nanotechnology, vol. 1, pp. 94-100, 2010.

[8] H.-L. Zhao, H.-B. Shen, H.-Z. Wang, and L.-S. Li, "Phosphinefree synthesis of high quality CdSe nanocrystals and their optical properties," Acta Physico Chimica Sinica, vol. 26, no. 3, pp. 691-694, 2010.

[9] Z. Juzheng, G. Shanmin, H. Baibiao, D. Ying, W. Ju, and L. Juan, "Preparation of CdSe nanocrystals with special morphologies," Progress in Chemistry, vol. 22, no. 10, pp. 1901-1910, 2010.

[10] Z. Lijuan, "Optical Properties of colloidal CdSe tetrapod nanocrystals," Journal of Infrared, Millimeter, and Terahertz Waves, vol. 29, no. 3, pp. 167-179, 2010.

[11] L. Liu, Q. Peng, and Y. Li, "Preparation of CdSe quantum dots with full color emission based on a room temperature injection technique," Inorganic Chemistry, vol. 47, no. 11, pp. 5022-5028, 2008.

[12] S. Liu, "Enhancing photoluminescence quenching and photoelectric properties of CdSe quantum dots with hole accepting ligands," Journal of Materials Chemistry, vol. 118, pp. 675-682, 2008.

[13] X. Chen, J. L. Hutchison, P. J. Dobson, and G. Wakefield, "Highly luminescent monodisperse CdSe nanoparticles synthesized in aqueous solution," Journal of Materials Science, vol. 44, no. 1, pp. 285-292, 2009.

[14] L. Li, H. Qian, and J. Ren, "Rapid synthesis of highly luminescent CdTe nanocrystals in the aqueous phase by microwave irradiation with controllable temperature," Chemical Communications, no. 4, pp. 528-530, 2005.

[15] B. Chen, H. Zhong, W. Zhang et al., "Highly emissive and colortunable $\mathrm{CuInS}_{2}$-based colloidal semiconductor nanocrystals: off-stoichiometry effects and improved electroluminescence performance," Advanced Functional Materials, vol. 22, no. 10, pp. 2081-2088, 2012.

[16] W. Zhang and X. Zhong, "Facile synthesis of ZnS-CuInS ${ }_{2}^{-}$ alloyed nanocrystals for a color-tunable fluorchrome and photocatalyst," Inorganic Chemistry, vol. 50, no. 9, pp. 4065-4072, 2011.

[17] C. Shouchun, Important Inorganic Chemical Reaction, Shanghai Scientific and Technical Publishers, 1963.

[18] D. Han, Synthesis And Optical Properties of II-IV Semiconductors and Doped Nanomarerials, Beijing University of Chemical Technology, 2009. 

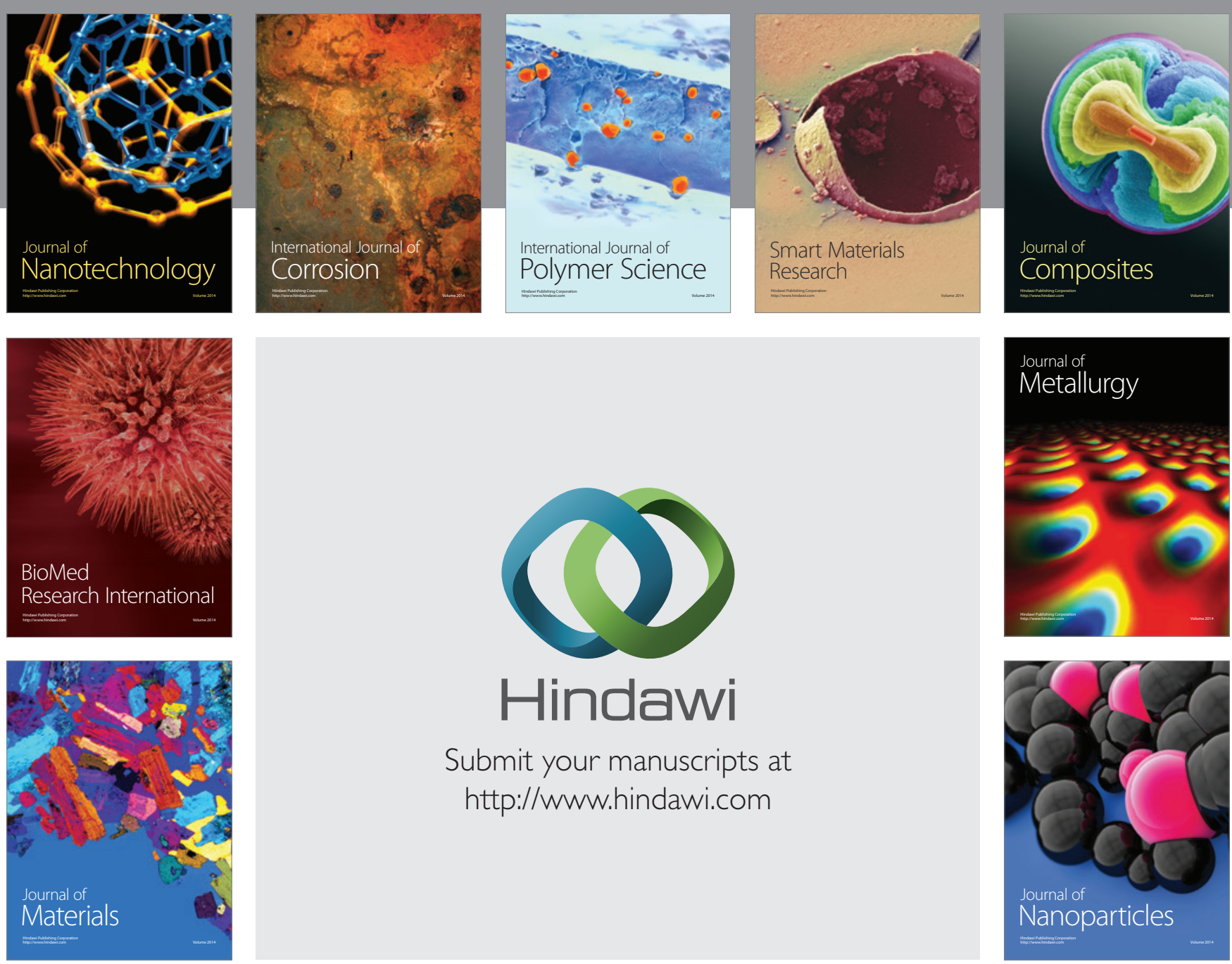

Submit your manuscripts at http://www.hindawi.com
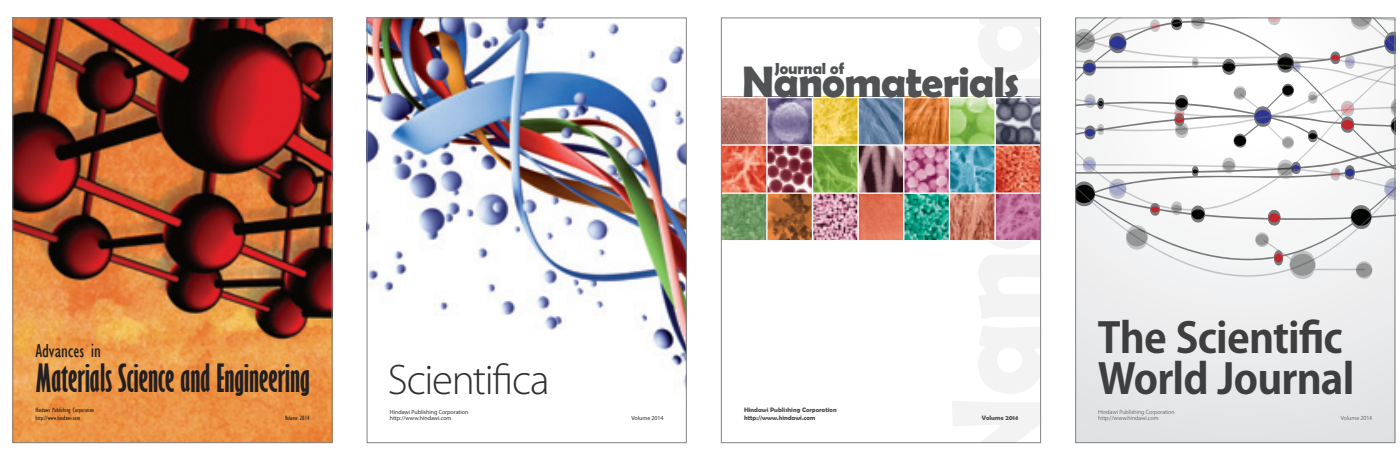

\section{The Scientific World Journal}
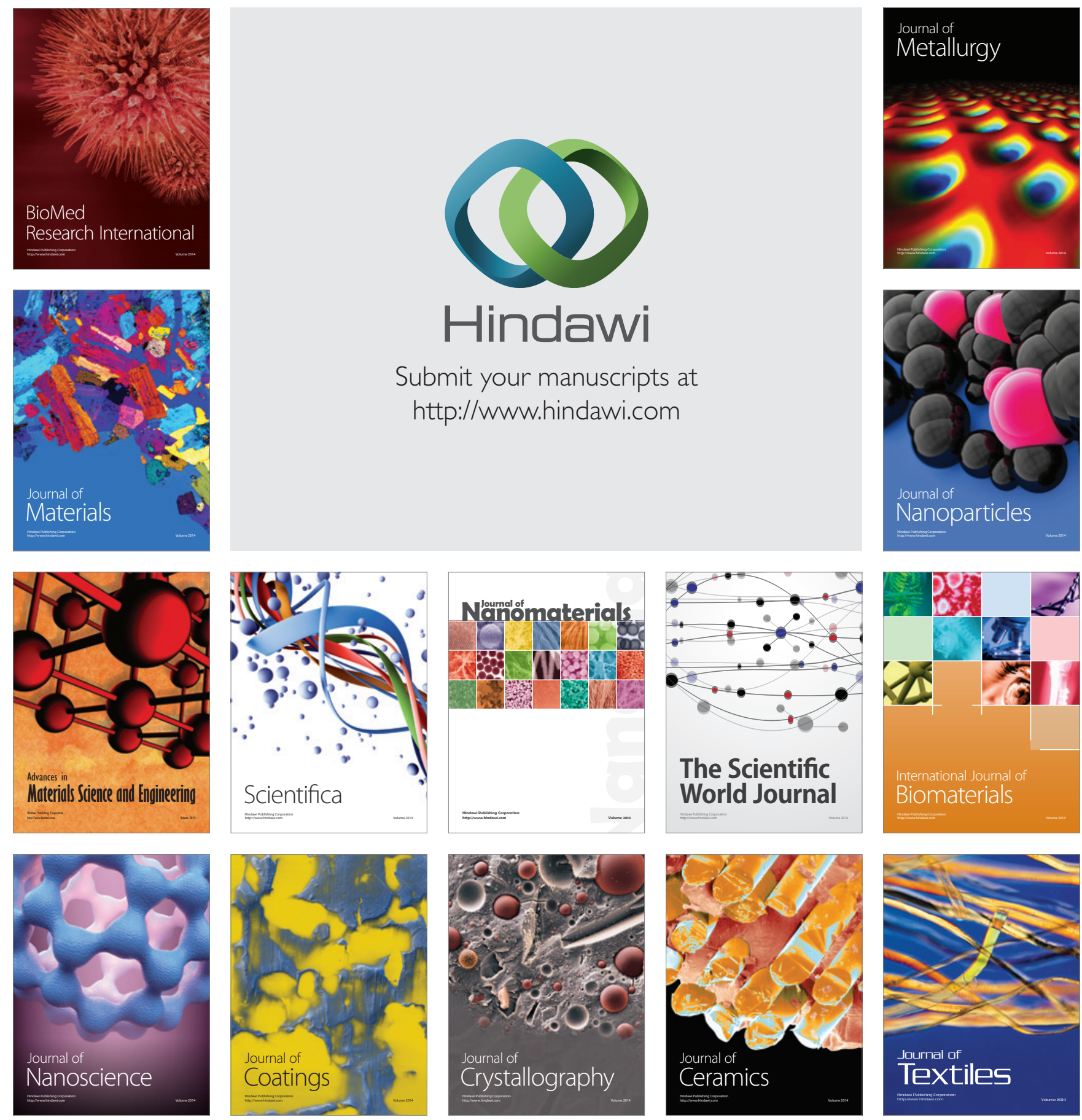